\title{
Ileocolic perforation secondary to sodium polystyrene sulfonate in sorbitol use: A case report
}

\author{
Vincent Trottier MD FRCSC ${ }^{1}$, Sébastien Drolet MD ${ }^{1}$, Mohib W Morcos MD²
}

\begin{abstract}
V Trottier, S Drolet, MW Morcos. Ileocolic perforation secondary to sodium polystyrene sulfonate in sorbitol use: A case report. Can J Gastroenterol 2009;23(10):689-690.

Hyperkalemia is a common condition encountered in medical and surgical patients. It can lead to various complications including cardiac arrhythmias. Sodium polystyrene sulfonate (SPS) in sorbitol is an ion-exchange resin that can be used to treat hyperkalemia. It can be used in enema or in oral form. The present article describes the case of an intensive care unit patient who experienced severe, diffuse, intestinal perforation induced by the use of SPS-sorbitol, requiring multiple laparotomies, followed by a brief review of the relevant literature and recommendations regarding the use of SPS-sorbitol.
\end{abstract}

Key Words: Intestinal perforation; Kayexalate; Sodium polystyrene sulfonate; Sorbitol

Wyperkalemia is a frequent condition encountered with Lintensive care unit (ICU) patients and can lead to lifethreatening cardiac arrhythmias. Sodium polystyrene sulfonate (SPS, Kayexalate, Roxanne Laboratories, USA) in sorbitol is an ion-exchange resin commonly used to treat hyperkalemia. A case of SPS-sorbitol-induced small bowel perforation is described, followed by a review of the relevant literature.

\section{CASE PRESENTATION}

A 24-year-old woman with new-onset partial-complex epilepsy diagnosed two years previously who had become refractory to medical treatment, was admitted to the ICU to undergo barbituric coma for burst suppression electroencephalogram therapy. After two days of thiopental infusion, burst suppression was initially achieved. A low-dose noradrenaline perfusion was necessary to counterbalance the hypotensive effect of thiopental. On day 4, the patient developed acute renal failure and hyperkalemia (serum potassium $6.8 \mathrm{mmol} / \mathrm{L}$ ). She received $30 \mathrm{~g}$ of SPS-sorbitol by nasogastric tube twice on the same day. The following day, a small bowel ileus was noted on physical examination and on an abdominal x-ray. The following day, the patient underwent a $50 \mathrm{~g}$ SPS-sorbitol enema. An abdominal computed tomography scan was performed on day 7 for continuing ileus, and showed small bowel distension and bowel wall thickening, without signs of obstruction. Two doses of intravenous neostigmine were administered on day 8 and day 9 to stimulate intestinal motility and relieve the ileus, without

\section{Une perforation iléocolique secondaire à l'utilisation de sulfonate de polystyrène de sodium associé à du sorbitol : Un rapport de cas}

\begin{abstract}
L'hypercalcémie est courante en milieu médical et chirurgical. Elle peut provoquer diverses complications, y compris l'arythmie cardiaque. Le sulfonate de polystyrène de sodium (SPS) associé au sorbitol est une résine d'échange ionique qu'on peut utiliser pour traiter l'hypercalcémie. On peut l'administrer sous forme de lavement ou sous forme orale. Le présent article décrit le cas d'une patiente aux soins intensifs qui a souffert d'une grave perforation intestinale diffuse induite par l'utilisation de SPS-sorbitol et a exigé de multiples laparotomies. Suit une brève analyse des publications pertinentes et des recommandations au sujet de l'utilisation de SPS-sorbitol.
\end{abstract}

success. On day 16, the patient developed unexplained fever, hypotension and a rigid, distended abdomen. An abdominal compartment syndrome was diagnosed and a laparotomy was performed. Purulent peritonitis was found, with patchy transmural small bowel necrosis. A right hemicolectomy (with a $40 \mathrm{~cm}$ resection of the ileum), an ileostomy and a temporary abdominal closure were performed. The pathological examination showed multifocal, acute ulceration of the ileum, patchy transmural necrosis and SPS crystal deposition within the intestinal mucosa (Figure 1). The postoperative course was complicated by additional necrosis of a $20 \mathrm{~cm}$ portion of the distal small bowel on day 24, requiring resection and ileostomy revision. The abdomen was closed with a third operation on day 29. The patient had no other abdominal problem during her hospitalization.

\section{DISCUSSION}

SPS-sorbitol-induced colonic perforation has been reported in renal transplant, neonate and burn patients after its use in enemas or orally (1-3). Sorbitol was incriminated in animal experiments performed by Lillemoe in 1987 (1). The experiment evaluated the colonic effects of different enemas in uremic and nonuremic rats. Sorbitol-containing enemas led to pathological changes in all uremic rats and in $65 \%$ of nonuremic rats. No pathological changes were noted in SPS enemas performed without sorbitol (1). Sorbitol is an osmotic laxative that is usually added to SPS preparations to reduce the risk of constipation

${ }^{1}$ Department of General Surgery; ${ }^{2}$ Department of Pathology, Centre Hospitalier Affilié Universitaire de Québec, Pavillon l'Enfant-Jésus,

Quebec City, Quebec

Correspondence: Dr Vincent Trottier, Department of General Surgery, Centre Hospitalier Affilié Universitaire de Québec, Pavillon l'Enfant-Jésus, 1401

$18^{e}$ Rue Québec, Quebec City, Quebec G1J 124. Telephone 418-649-0252, fax 418-649-5579, e-mail R8155@hotmail.com

Received for publication November 21, 2008. Accepted November 23, 2008 


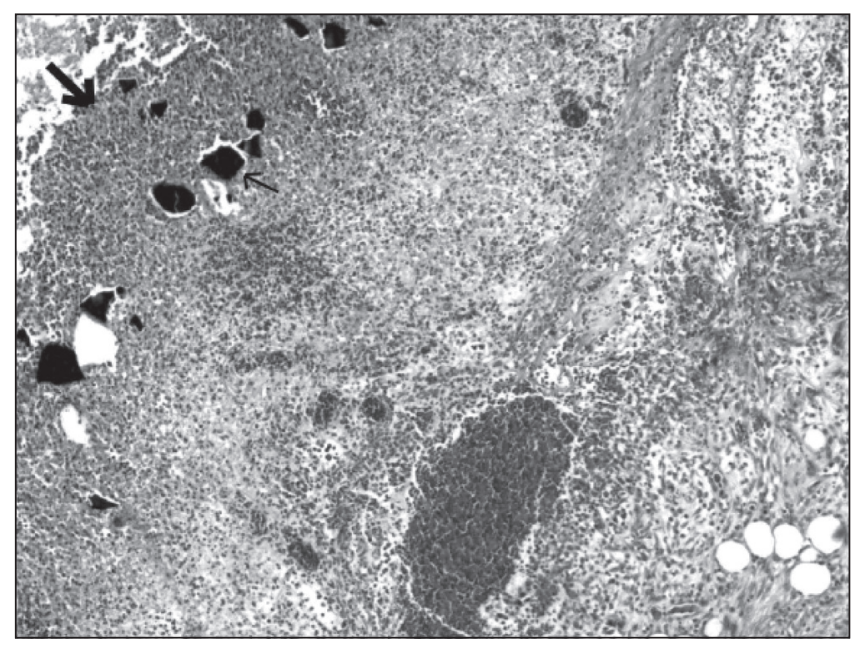

Figure 1) Base of an ulcer showing necrotic debris (large arrow) replacing the intestinal mucosa, and sodium polystyrene sulfonate crystals (small arrow) within the ulcer and on the surface. Hematoxylin and eosin stain (original magnification $\times 40$ )

and fecal impaction. Sorbitol is poorly absorbed in the small bowel, where colonic bacteria metabolize it to short-chain organic fatty acids allowing for their absorption in the colon. When present in the lumen in excess of what can be absorbed, fatty acids osmotically increase the amount of fluid in the colon. Some authors recommend the use of SPS alone in enemas, and to perform evacuating enemas after using it to minimize the risk of impaction (4). Risk factors for colonic perforation with use of SPS-sorbitol reported in the literature include uremia, hypovolemia, hypotension, coagulation disorders and immunosuppression (5). Our patient presented with hypotension (corrected by noradrenaline perfusion) and acute renal failure. Additionally, the ileus (caused by thiopental use) may have increased the time of contact between SPS-sorbitol and the colonic mucosa. Interestingly, reported cases in the literature all showed early signs of perforation (within two days), while our patient was diagnosed 12 days after her first dose of SPS. Noradrenaline is known to reduce the splanchnic flow and was used between days 2 and 12 . Neostigmine trials to stimulate intestinal motility and relieve the ileus may have contributed to increased intraluminal pressure exerted on a weakened wall. The majority of reported cases are associated with enema use. In our case, the lesions were mainly at the ileum; the oral use of an SPS-sorbitol preparation was probably responsible for this presentation.

\section{CONCLUSION}

Surgeons should be aware of this possible etiology when facing a situation of unexplained patchy focal necrosis and intestinal perforation. Physicians using SPS-sorbitol to treat hyperkalemia should also be familiar with this potentially lifethreatening complication. SPS-sorbitol should be used with caution in patients with uremia, hypotension or ileus. It may be preferable to avoid adding sorbitol to SPS in these patients and to use a laxative formula to wash away the SPS after its ion binding has occurred.

ACKNOWLEDGEMENT: The authors thank Dr Jeremy Jass, McGill University Health Centre, Montreal, Quebec.

\section{REFERENCES}

1. Lillemoe KD, Romolo JL, Hamilton SR, Pennington LR, Burdick JF, Williams GM. Intestinal necrosis due to sodium polystyrene (Kayexalate ${ }^{\circledR}$ ) in sorbitol enemas: Clinical and experimental support for the hypothesis. Surgery 1987;101:266-72.

2. Bennett LN, Myers TM, Lambert GH. Cecal perforation associated with sodium polystyrene sulfonate-sorbitol enemas in a 650 gram infant with hyperkalemia. Am J Perinatol 1996;13:167-70.

3. Cheng ES, Stringer KM, Pegg SP. Colonic necrosis and perforation following oralsodium polystyrene sulfonate (resonium $A \circledR$ / Kayexalate ${ }^{\circledR}$ ) in a burn patient. Burns 2002;28:189-90.

4. Taylor WF, Rhodes DF, Lee WM, Fitts CT. Colonic necrosis with kayexalate-sorbitol enemas after renal transplantation. Ann Intern Med 1989;111:947-9.

5. Rashid A, Hamilton SR. Necrosis of the gastrointestinal tract in uremic patients as a result of sodium polystyrene sulfonate (Kayexalate®) in sorbitol. Am J Surg Pathol 1997;21:60-9. 


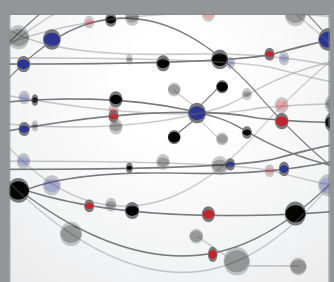

The Scientific World Journal
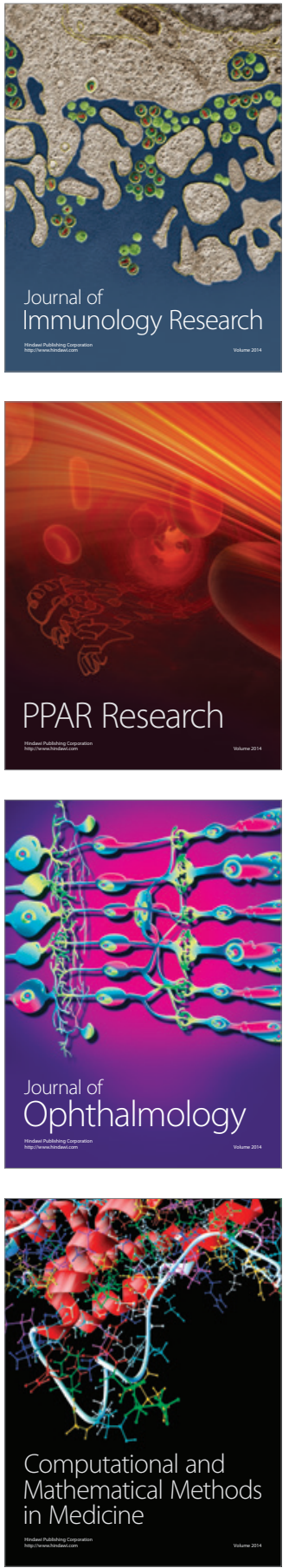

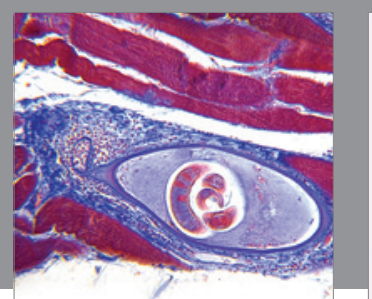

Gastroenterology Research and Practice

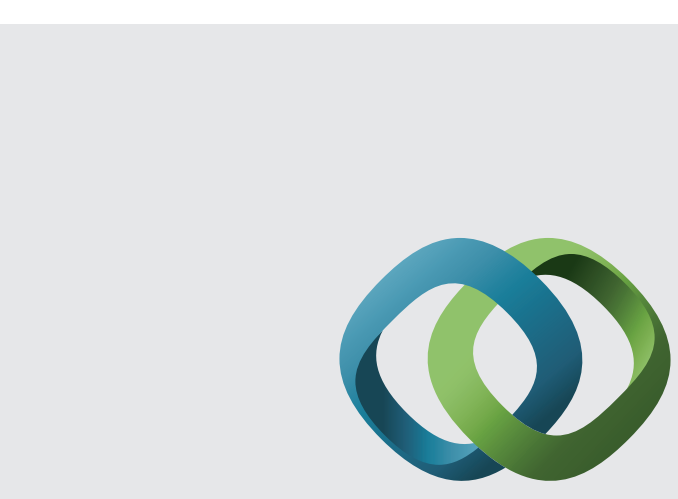

\section{Hindawi}

Submit your manuscripts at

http://www.hindawi.com
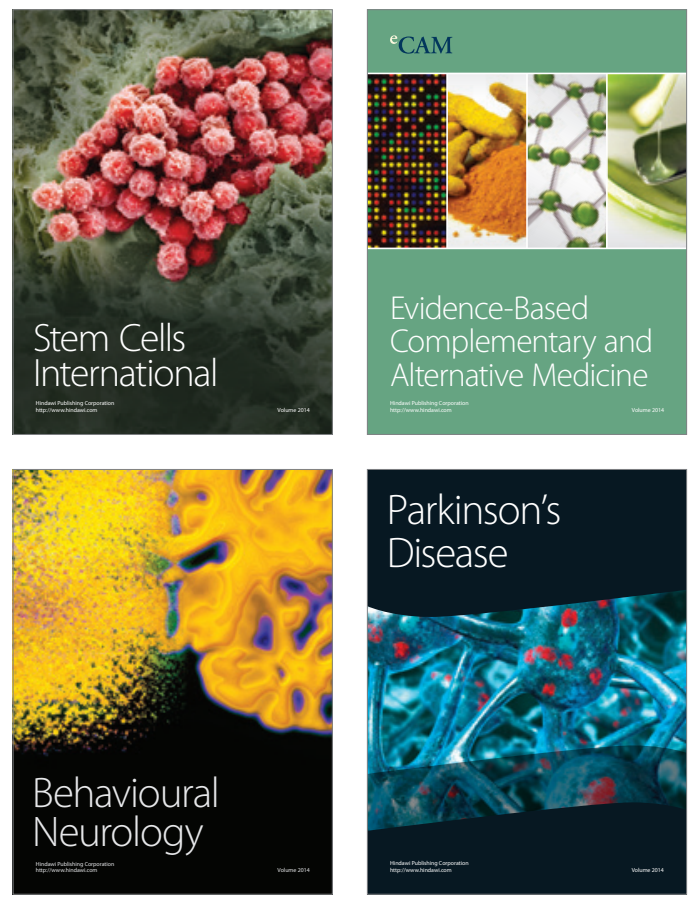
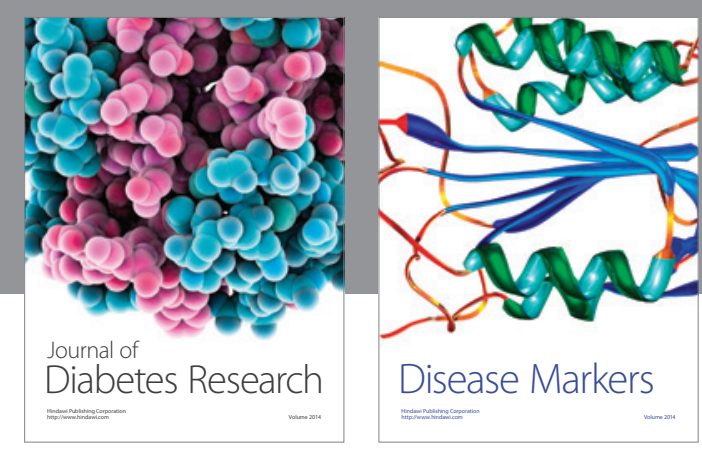

Disease Markers
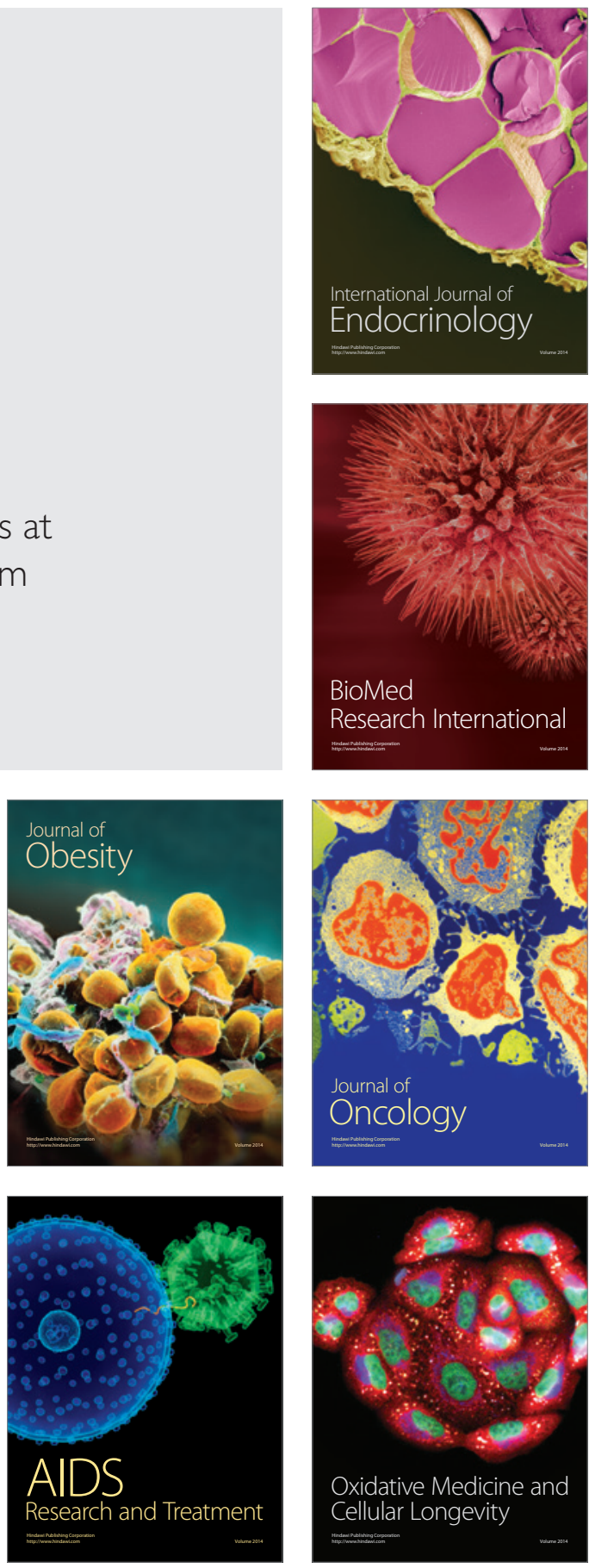